University of Nebraska - Lincoln

DigitalCommons@University of Nebraska - Lincoln

$2-22-2003$

\title{
Cooperative effects in one-dimensional chains of three-center hydrogen bonding interactions
}

\author{
Ruben D. Parra \\ DePaul University, rparra1@depaul.edu
}

Satya S. Bulusu

University of Nebraska-Lincoln, sbulusu@iiti.ac.in

Xiao Cheng Zeng

University of Nebraska-Lincoln, xzeng1@unl.edu

Follow this and additional works at: https://digitalcommons.unl.edu/chemzeng

Part of the Chemistry Commons

Parra, Ruben D.; Bulusu, Satya S.; and Zeng, Xiao Cheng, "Cooperative effects in one-dimensional chains of three-center hydrogen bonding interactions" (2003). Xiao Cheng Zeng Publications. 37.

https://digitalcommons.unl.edu/chemzeng/37

This Article is brought to you for free and open access by the Published Research - Department of Chemistry at DigitalCommons@University of Nebraska - Lincoln. It has been accepted for inclusion in Xiao Cheng Zeng Publications by an authorized administrator of DigitalCommons@University of Nebraska - Lincoln. 


\title{
Cooperative effects in one-dimensional chains of three-center hydrogen bonding interactions
}

\author{
Rubén D. Parra ${ }^{\mathrm{a})}$ \\ Department of Chemistry, DePaul University, Chicago, Illinois 60614 \\ Satya Bulusu and X. C. Zeng \\ Department of Chemistry University of Nebraska-Lincoln, Lincoln, Nebraska 68588
}

(Received 3 October 2002; accepted 13 November 2002)

\begin{abstract}
Cooperative effects in a one-dimensional network of intermolecular bifurcated hydrogen bonding interactions are investigated by means of $a b$ initio calculations. The trans-trans conformation of the diformamide molecule is used as a basic motif to model a chain of bifurcated $\mathrm{H}$ bonds. In this model system, the two proton-acceptor atoms belong to the same molecule. The one-dimensional network is modeled then by periodically stacking up to 12 molecules of the unit motif. Different indicators of H-bond strength such as energetic, structural, dielectric, vibrational frequencies, and isotropic chemicals shifts consistently show significant cooperative effects in the chains. The dissociation energy in the dimer is calculated to be $9.88 \mathrm{kcal} / \mathrm{mol}$, while that of the strongest interaction in the decamer is calculated to be $26.12 \mathrm{kcal} / \mathrm{mol}$ (164\% increase in cooperativity). Thus, although three-center $\mathrm{H}$ bonds can be viewed as a consequence of proton deficiency, in some cases they may also be viewed as the natural result of an interaction that is itself energetically favorable and capable of competing with the more conventional two-center $\mathrm{H}$ bonds. Natural bond orbital analysis reveals substantial charge delocalization within each molecule, and charge transfer along the chains. Interestingly, this charge delocalization makes the system a good candidate for resonance-assisted $\mathrm{H}$ bonding which in turn increases the covalent character of this type of bifurcated H-bonding interaction. (C) 2003 American Institute of Physics. [DOI: 10.1063/1.1535441]
\end{abstract}

\section{INTRODUCTION}

An important concept in the theory of hydrogen bonding is hydrogen-bond (H-bond) cooperativity, which is typically described as the nonadditive enhancement of an $\mathrm{H}$ bond by the formation of another $\mathrm{H}$ bond with either the proton donor or proton acceptor of the first $\mathrm{H}$ bond. ${ }^{1-10}$ Considerable attention has been given to the study of cooperative effects in molecular clusters containing conventional two-center $\mathrm{H}$ bonds, which involve one proton donor and one acceptor. ${ }^{1-17}$ Some researchers have investigated the cooperative or nonadditive effects of hydrogen-bonding chains. ${ }^{18}$ King and Weinhold ${ }^{19}$ showed that even relatively weak proton donors such as HCN could present robust cooperative effects in large linear $(\mathrm{HCN})_{n}$ clusters. Suhai ${ }^{20}$ carried out ab initio crystal orbital calculations on quasi-one-dimensional, infinite periodic lattice of water molecules as a first step to model cooperative effects in various modifications of ice. Ludwig et $a .^{21}$ found strong cooperative effects in linear clusters of trans- $N$-methylacetamide; these authors also studied the hydrogen bonding of liquid $N$-methylacetamide using the quantum cluster equilibrium (QCE) methodology and suggested the possibility of extending this methodology to a much broader spectrum of $\mathrm{H}$-bonded liquids. Guo et al. ${ }^{22}$ investigated many-body effects in systems of peptide H-bonded networks; an encouraging conclusion from these authors is

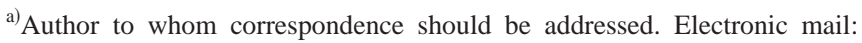
rparra1@depaul.edu
}

that polarizable molecular mechanics in combination with $a b$ initio and density functional methods could be a useful approach for studying protein structures, thanks in part to the ability of a polarizable molecular mechanics procedure to recover a major portion of cooperative effects. Dannenberg et $a l .{ }^{23}$ recently reported an unusually high degree of cooperativity for hydrogen-bonding chains of formamide molecules and its implications for protein-folding models.

Cooperative effects in bifurcated $\mathrm{H}$ bonds, however, have been much less investigated. Recent studies have discussed cooperative effects in terms of the two-center components of the bifurcated $\mathrm{H}$ bond. These studies support the notion that intermolecular bifurcated $\mathrm{H}$-bond formation is a process that gives rise to negative cooperative effects. ${ }^{24,25}$ For intramolecular bifurcated $\mathrm{H}$ bonds, examples of negative and positive cooperative effects have been reported. ${ }^{26-28}$ Very few studies of cooperative effects in chains of bifurcated $\mathrm{H}$ bonds have been reported. Masunov and Dannenberg $^{29}$ investigated one-dimensional hydrogenbonding aggregates, chains and ribbons, of urea and thiourea; these authors found the cooperative interactions for the urea and thiourea chains to be similar, whereas the cooperative interactions for both ribbons were found to be negligible. Wu et al. ${ }^{30}$ reported the first experimental determination of the carbonyl ${ }^{17} \mathrm{O}$ electric-field-gradient (EFG) tensor and chemical-shift tensor; the strong hydrogen-bonding effects on these quantities were studied by systematically modeling the $\mathrm{H}$-bond network in crystalline urea with several molecular clusters including bifurcated and other multicenter 


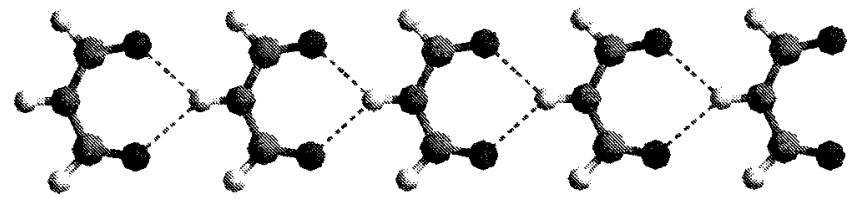

FIG. 1. Schematic structure showing the bifurcated H-bonding pattern in linear trans,trans-diformamide chains.

$\mathrm{H}$ bonds. It should be said that the fundamental role of bifurcated $\mathrm{H}$ bonds in proteins, DNA crystal structures, and other biologically relevant systems have been amply demonstrated. $^{31,32}$ For example, parallel and antiparallel $\beta$ sheets have been shown to contain a network of bifurcated $\mathrm{H}$ bonds where each carbonyl $\mathrm{O}$ atom accepts a pair of $\mathrm{H}$ bonds, one from a peptide $\mathrm{N}-\mathrm{H}$ and one from a $\mathrm{C}_{\alpha}-\mathrm{H}$ group of the preceding residue. ${ }^{3,33}$

In this paper, we report the cooperative effects in a chain of bifurcated three-center $\mathrm{H}$ bonds. Two types of bifurcated H-bond interactions can be distinguished: (a) one that involves a hydrogen atom and two acceptor atoms (denoted $\mathrm{A}_{1} \mathrm{HA}_{2}$ ), and (b) one that involves one acceptor atom and two hydrogen atoms (denoted $\mathrm{H}_{1} \mathrm{AH}_{2}$ ). The former type is the subject of this paper; the latter type has been modeled using molecular clusters of urea. ${ }^{29,30}$ Cooperative effects are highlighted using several indicators such as the energy per bifurcated $\mathrm{H}$ bond, defined as the interaction energy divided by the number of bifurcated $\mathrm{H}$ bonds present in the chain. Other indicators of cooperativity are the stretching of the $\mathrm{X}-\mathrm{H}$ group, the $\mathrm{X}-\mathrm{H}$ bond length, the $\mathrm{H}$-bond length, the $\mathrm{X}-\mathrm{H}$ proton chemical shifts, and the chain dipole moment.

\section{MODEL SYSTEM}

A network of one-dimensional bifurcated $\mathrm{H}$ bonds can be built by stacking periodically a structure motif in the direction that favors a bifurcated $\mathrm{H}$-bonding interaction. In this study, we have chosen the trans-trans conformation of the diformamide molecule, $d f a$, as our basic motif to model a chain of bifurcated $\mathrm{H}$ bonds of the $\mathrm{A}_{1} \mathrm{HA}_{2}$ type. In this model system, the two proton-acceptor atoms belong to the same molecule as depicted in Fig. 1.

The one-dimensional network will be modeled then by periodically stacking up to 12 molecules of the unit motif. This size should be sufficient to unravel the basic features of the interactions. The relatively small size of $d f a$ allows for relatively high-level calculations to be performed. It also allows us to focus our attention to the H-bond interactions in great detail as no other major interactions are taking place.

\section{COMPUTATIONAL DETAILS}

All the computations were carried out using the GAUSSIAN 98 program. ${ }^{34}$ The geometries of the different systems were optimized at the B3LYP/6-31+G(d) level. The same level was used to compute harmonic vibrational frequencies and zero-point energy corrections to the electronic energies. The optimized geometries were used to compute single point energy calculations at the MP2/6-31+G(d), and $\mathrm{MP} 2 / 6-311++\mathrm{G}(2 d, 2 p)$ levels. Natural bond orbital
TABLE I. Interaction energies $(\mathrm{kcal} / \mathrm{mol})$ for clusters of diformamide, $(d f a)_{n}, n=2-5$.

\begin{tabular}{|c|c|c|c|c|}
\hline \multirow[b]{2}{*}{$n$} & \multicolumn{2}{|c|}{$\Delta E(\mathrm{HF})$} & \multicolumn{2}{|c|}{$\Delta E(\mathrm{MP} 2)$} \\
\hline & $\begin{array}{c}6-311+ \\
+\mathrm{G}(2 d, 2 p)\end{array}$ & $6-31+\mathrm{G}(d)$ & $\begin{array}{c}6-311+ \\
+\mathrm{G}(2 d, 2 p)\end{array}$ & $6-31+\mathrm{G}(d)$ \\
\hline 2 & -9.77 & -10.78 & -9.83 & -9.88 \\
\hline 3 & -24.04 & -25.40 & -22.85 & -22.98 \\
\hline 4 & -39.50 & -41.68 & -37.23 & -37.42 \\
\hline 5 & -58.75 & -58.75 & -52.52 & -52.52 \\
\hline
\end{tabular}

(NBO) analysis were performed on wave functions calculated at the HF/6-31+ G $(d)$ level. Finally, ${ }^{1} \mathrm{H}-\mathrm{NMR}$ chemical shielding constants were computed at the B3LYP/6-31 $+\mathrm{G}(d)$ level.

\section{RESULTS}

Energetics. Table I shows the counterpoise-corrected interaction energies, $\Delta E$, of the fully optimized linear clusters up to $n=5$ computed using the $6-31+\mathrm{G}(d)$ and the 6-11 $++\mathrm{G}(2 d, 2 p)$ basis sets. Both basis sets give MP2 values that are within $0.20 \mathrm{kcal} / \mathrm{mol}$. Except for the pentamer, the smaller basis set gives HF values that differ by up to 2.18 $\mathrm{kcal} / \mathrm{mol}$ from those obtained with the higher basis set. The interaction energy of the dimer at the higher MP4(SDTQ)/6-31+G(d) level is $9.79 \mathrm{kcal} / \mathrm{mol}$, which is very close to that at the MP2 level and same basis set. For computational convenience and given its relatively good performance, the interaction energies for the larger clusters were computed at the MP2/6-31+G(d) level.

Table I shows that in general the HF stabilization energies are more negative than their MP2 counterparts. That is, correlation corrections to the interaction energies turn out repulsive for the systems considered. To rationalize this finding, we need to consider both the dispersion interaction, which is wholly a correlation effect, and the electron correlation correction to the electrostatic interaction between molecules. ${ }^{35,36}$ Since dispersion interaction energies are attractive, the overall repulsive correlation correction to the interaction energies is to be found in the electrostatic component of the interaction. To a first approximation, the correlation correction of the electrostatic interaction may be approximated by the electrostatic interactions between the correlation-corrected dipole moments of each interacting subunit. So, for example, the HF/6-31+ G(d) average dipole moment of the $(d f a)_{2}$ and $(d f a)_{4}$ clusters are $7.61 \mathrm{D}$ and 8.48 D, respectively, while the corresponding MP2 dipoles are 6.64 D and 7.50 D for dimer and tetramer, respectively. Because the average MP2 dipole for each cluster is over 0.95 D smaller than its SCF counterpart, the correlation correction to the electrostatics is repulsive in character. Since the electrostatic interaction is often large, the effect of electron correlation on it can be important in giving an accurate description of the interaction. This is particularly true for the diformamide clusters where the attractive character of the dispersion interaction is offset by the repulsive character of the correlation-corrected electrostatic interaction. Szczesniak et $a l .{ }^{37}$ found a similar result for the water dimer. These authors found that simple addition of dispersion energy to SCF 
TABLE II. Dissociation energies $(\mathrm{kcal} / \mathrm{mol})$ before, $D_{e}$, and after, $D_{0}$, zero-point corrections, in bifurcated hydrogen-bonded chains of $(d f a)_{n}$.

\begin{tabular}{ccccccc}
\hline \hline & & & & & \multicolumn{2}{c}{ Cooperativity $^{\mathrm{a}}$} \\
\cline { 6 - 7 }$n$ & $D_{e}$ & $D_{e} /(n-1)$ & $D_{0}$ & $D_{0} /(n-1)$ & $D_{e}$ & $D_{0}$ \\
\hline 2 & 9.88 & 9.88 & 8.73 & 8.73 & & \\
3 & 22.98 & 11.49 & 20.49 & 10.25 & 3.22 & 3.03 \\
4 & 37.42 & 12.47 & 33.52 & 11.17 & 3.89 & 3.67 \\
5 & 52.52 & 13.13 & 47.20 & 11.80 & 4.33 & 4.09 \\
6 & 67.97 & 13.59 & 61.22 & 12.24 & 4.64 & 4.39 \\
7 & 83.62 & 13.94 & 75.43 & 12.57 & 4.87 & 4.61 \\
8 & 99.4 & 14.20 & 89.77 & 12.82 & 5.04 & 4.78 \\
9 & 115.25 & 14.41 & 104.18 & 13.02 & 5.17 & 4.91 \\
10 & 131.16 & 14.57 & 118.64 & 13.18 & 5.28 & 5.01 \\
\hline \hline
\end{tabular}

${ }^{a}$ Cooperativity defined as $\left.\left[\Delta Q_{n}-(n-1) \Delta Q_{2}\right] /(n-2)\right]$, where $\Delta Q_{n}$ is the dissociation energy of the cluster of size $n$ and $\Delta Q_{2}$ is that of the dimer.

interactions did not correctly reproduce the full correlation energy arising from MP2 calculations. The authors established that the electrostatic correlation correction was largely responsible for the discrepancy.

Table II reports the dissociation energies of the clusters before, $D_{e}$, and after, $D_{0}$, zero-point vibrational energy corrections. Also shown are the corresponding average dissociation energies. The increase in the dissociation energies per hydrogen bond upon enlarging the size of the chain is significant. For example, while $D_{e}$ is $9.88 \mathrm{kcal} / \mathrm{mol}$ for the dimer, the average $D_{e}$ of the two bifurcated $\mathrm{H}$ bonds present in the trimer is $11.49 \mathrm{kcal} / \mathrm{mol}$, i.e., an increase of about $16 \%$. The corresponding increase for the decamer is about 47\%. Expressed another way, cooperative enhancement stabilizes the average H-bond interaction in the decamer by about $42.24 \mathrm{kcal} / \mathrm{mol}$; this is equivalent to adding 4.3 "new" bifurcated hydrogen bonds beyond the sum of pairwiseadditive dimer $\mathrm{H}$ bonds. The large increase of the average bond dissociation energy is a good indication of the extent of H-bond cooperativity.

A convenient measure of energy cooperativity is given as

$$
\text { cooperativity }=\left[\Delta Q_{n}-(n-1) \Delta Q_{2}\right] /(n-2),
$$

where $Q$ is the property of interest. The corresponding cooperative values for $D_{e}$ and $D_{0}$ are displayed in Table II. Although the relative cooperative enhancement is largest for the trimer, further appreciable increases are still apparent in the larger clusters. The trends in the $D_{e}$ values per bifurcated $\mathrm{H}$ bond and in the corresponding cooperativity factors with increasing chain length are illustrated in Fig. 2 by plotting them versus $1 / n$, where $n$ is the number of diformamide molecules in the cluster. An almost perfect linear correlation is observed for each quantity. The relation between $D_{e}$ and $1 / n$ can be expressed by a linear correlation of the form

$$
D_{e}=-11.88(1 / n)+15.62 \text {. }
$$

Analogously, the linear correlation between cooperativity and $1 / n$ is

$$
\text { cooperativity }=-8.89(1 / n)+6.14 \text {. }
$$

From Eq. (2), we find that the average $D_{e}$ approaches 15.62 $\mathrm{kcal} / \mathrm{mol}$ as $n \rightarrow \infty$. This value suggests an asymptotic value

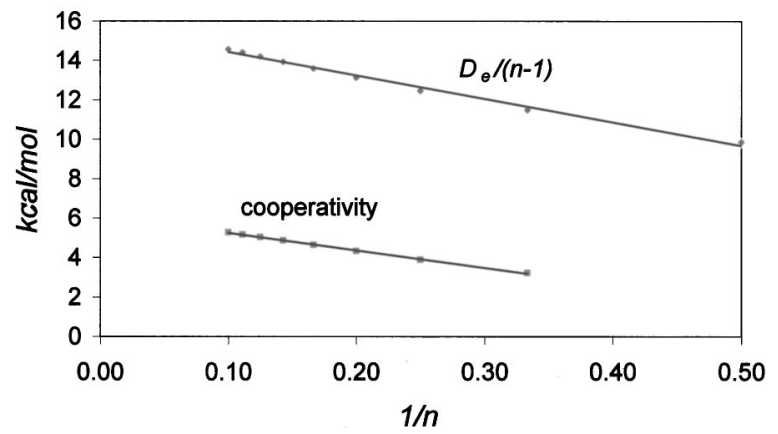

FIG. 2. Plots of average dissociation energies, $D_{e} /(n-1)$, and cooperativity factor vs $1 / n$ for linear diformamide clusters.

of about $5.74 \mathrm{kcal} / \mathrm{mol}(15.62-9.88 \mathrm{kcal} / \mathrm{mol})$ or an increment of $42 \%$ with respect to the dimer. From Eq. (3), we find that the cooperative factor converges to $6.14 \mathrm{kcal} / \mathrm{mol}$; a value close to that derived from Eq. (2). These results lead to an average asymptotic cooperativity value of $5.94 \mathrm{kcal} / \mathrm{mol}$ results for $D_{e}$.

The relation between $D_{0}$ and $1 / n$ is also expressed by a linear correlation of the form

$$
D_{0}=-11.31(1 / n)+14.18 \text {. }
$$

The corresponding cooperativity factor is

$$
\text { cooperativity }=-8.67(1 / n)+5.86 \text {. }
$$

Again, the asymptotic cooperativity values estimated from Eq. (4) $(5.45 \mathrm{kcal} / \mathrm{mol})$ and Eq. (5) $(5.86 \mathrm{kcal} / \mathrm{mol})$ are close to each other and lead to an average value of 5.66 $\mathrm{kcal} / \mathrm{mol}$ which is in turn very close to the average estimate found for $D_{e}(5.94 \mathrm{kcal} / \mathrm{mol})$. Thus, adding zero-point energy corrections does not have any significant effect on the cooperative energy estimated for the infinite size chain.

The energy required to dissociate a given $(d f a)_{n}$ cluster into various fragment clusters

$$
(d f a)_{n} \rightarrow(d f a)_{n-b}+(d f a)_{b}
$$

is also frequently used to asses the cooperative enhancement of the H-bond interaction upon enlarging the size of the chain. Here $n$ is the number of molecules in the chain, and $b$ goes from 1 to 5 depending on the original cluster size $n$. This approach, which consists of breaking a single bifurcated $\mathrm{H}$ bond, gives higher weight to bulk like $\mathrm{H}$ bonds. The results at the MP2/6-31+ $\mathrm{G}(d)$ level, without zero-point corrections, for the various clusters are displayed in Table III and in Fig. 3. A substantial and progressive cooperative enhancement is manifested as the chain grows. For example, the energy to fragment a trimer into a dimer and a monomer is $13.10 \mathrm{kcal} / \mathrm{mol}$ (cooperative increase of 33\%), and that to form a nonamer plus monomer from the decamer cluster is $15.91 \mathrm{kcal} / \mathrm{mol}$ (61\% increase). The percentage enhancement increases dramatically for the more bulklike bifurcated $\mathrm{H}$ bonds. Figure 3 suggests that an asymptotic value for the cooperative increase should be close to $26.12 \mathrm{kcal} / \mathrm{mol}$.

Geometries. Full geometry optimization shows perfectly symmetric bifurcated $\mathrm{H}$ bonds for each cluster. Cooperative effects bring about notorious changes on the intramolecular structural parameters of the diformamide molecule. The ex- 
TABLE III. Energy $(\mathrm{kcal} / \mathrm{mol})$ required to dissociate a given $(d f a)_{n}$ cluster into various fragments according to the reaction $(d f a)_{n} \rightarrow(d f a)_{n-b}$ $+(d f a)_{b}$.

\begin{tabular}{cccccc}
\hline \hline & \multicolumn{5}{c}{$b$} \\
$n$ & 1 & 2 & 3 & 4 & 5 \\
\hline 2 & 9.88 & & & & \\
3 & 13.10 & & & & \\
4 & 14.44 & 17.66 & & & \\
5 & 15.10 & 19.66 & & & \\
6 & 15.45 & 20.67 & 22.01 & & \\
7 & 15.65 & 21.22 & 23.22 & & \\
8 & 15.78 & 21.55 & 23.90 & 24.56 & \\
9 & 15.85 & 21.75 & 24.30 & 25.31 & \\
10 & 15.91 & 21.88 & 24.56 & 25.77 & 26.12 \\
\hline \hline
\end{tabular}

tent of the changes depends on the size of the cluster and on the position of the molecule within the cluster. Table IV shows relevant bond distances for the optimized clusters. An increase in the $r(\mathrm{~N}-\mathrm{H})$ and $r(\mathrm{C}=\mathrm{O})$ bond lengths and a concomitant decrease in the $r(\mathrm{C}-\mathrm{N})$ bond length is generally observed upon enlarging the size of the cluster.

The structural parameters for the leftmost molecule in Fig. 1 (with a free terminal $\mathrm{N}-\mathrm{H}$ ) quickly approach asymptotic values close to $1.016,1.394$, and $1.212 \AA$ for the $r(\mathrm{~N}-\mathrm{H}), r(\mathrm{C}-\mathrm{N})$, and $r(\mathrm{C}=\mathrm{O})$, respectively. Interestingly, $r(\mathrm{C}-\mathrm{N})$ is shortened by the same amount that the $\mathrm{C}=\mathrm{O}$ bond is stretched, i.e., $0.006 \AA$. The corresponding asymptotic values for the rightmost molecule (with free carbonyl groups) are more significant: $r(\mathrm{~N}-\mathrm{H})=1.022 \AA$, $r(\mathrm{C}-\mathrm{N})=1.391 \AA$, and $r(\mathrm{C}=\mathrm{O})=1.214 \AA$.

Cooperative effects are more evident in the interior molecules. Table $\mathrm{V}$ shows the bond lengths for the molecule

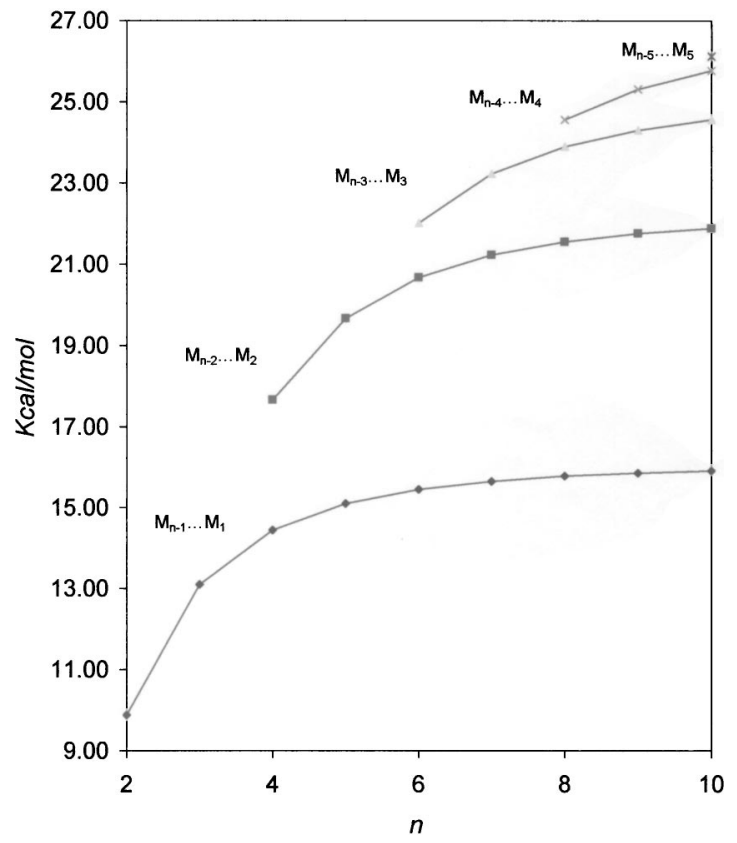

FIG. 3. Cooperative enhancement of the energy required to dissociate a given $(d f a)_{n}$ cluster into various fragment clusters: $(d f a)_{n} \rightarrow(d f a)_{n-b}$ $+(d f a)_{b}$. Here $n$ is the number of molecules in the chain, and $b$ goes from 1 to 5 depending on the original cluster size.
TABLE IV. Optimized bond lengths $(\AA)$ of $(d f a)_{n}$ clusters $(n=1-12)$ at B3LYP/6-31+G $(d)$ level. Data presented for monomers from leftmost to rightmost molecule in Fig. 1.

\begin{tabular}{|c|c|c|c|c|c|c|}
\hline$n$ & $r(\mathrm{~N}-\mathrm{H})$ & $r(\mathrm{C}-\mathrm{N})$ & $r(\mathrm{C}=\mathrm{O})$ & $r(\mathrm{O} \cdots \mathrm{H}-\mathrm{N})$ & $r(\mathrm{~N} \cdots \mathrm{N})$ & $r(\mathrm{O} \cdots \mathrm{H}-\mathrm{C})$ \\
\hline 1 & 1.0149 & 1.3996 & 1.2060 & & & \\
\hline \multirow[t]{2}{*}{2} & 1.0153 & 1.3957 & 1.2096 & 2.2785 & 4.5937 & 2.6969 \\
\hline & 1.0191 & 1.3941 & 1.2109 & & & \\
\hline \multirow[t]{3}{*}{3} & 1.0155 & 1.3946 & 1.2108 & 2.2120 & 4.5180 & 2.6537 \\
\hline & 1.0206 & 1.3889 & 1.2151 & 2.2251 & 4.5327 & 2.6315 \\
\hline & 1.0210 & 1.3925 & 1.2125 & & & \\
\hline \multirow[t]{4}{*}{4} & 1.0155 & 1.3942 & 1.2113 & 2.1937 & 4.4957 & 2.6380 \\
\hline & 1.0213 & 1.3875 & 1.2165 & 2.1585 & 4.4562 & 2.5885 \\
\hline & 1.0229 & 1.3870 & 1.2169 & 2.2097 & 4.5140 & 2.6115 \\
\hline & 1.0217 & 1.3919 & 1.2131 & & & \\
\hline \multirow[t]{5}{*}{5} & 1.0156 & 1.3940 & 1.2116 & 2.1848 & 4.4866 & 2.6296 \\
\hline & 1.0216 & 1.3870 & 1.2171 & 2.1407 & 4.4338 & 2.5726 \\
\hline & 1.0238 & 1.3855 & 1.2183 & 2.1420 & 4.4358 & 2.5674 \\
\hline & 1.0238 & 1.3862 & 1.2176 & 2.2036 & 4.5066 & 2.6036 \\
\hline & 1.0220 & 1.3916 & 1.2134 & & & \\
\hline \multirow[t]{6}{*}{6} & 1.0156 & 1.3939 & 1.2117 & 2.1816 & 4.4823 & 2.6269 \\
\hline & 1.0218 & 1.3867 & 1.2174 & 2.1318 & 4.4247 & 2.5641 \\
\hline & 1.0242 & 1.3849 & 1.2189 & 2.1239 & 4.4128 & 2.5510 \\
\hline & 1.0248 & 1.3847 & 1.2191 & 2.1353 & 4.4274 & 2.5589 \\
\hline & 1.0243 & 1.3859 & 1.2179 & 2.2007 & 4.5031 & 2.5999 \\
\hline & 1.0222 & 1.3914 & 1.2136 & & & \\
\hline \multirow[t]{7}{*}{7} & 1.0154 & 1.3939 & 1.2117 & 2.1783 & 4.4799 & 2.6256 \\
\hline & 1.0219 & 1.3866 & 1.2176 & 2.1266 & 4.4203 & 2.5598 \\
\hline & 1.0244 & 1.3846 & 1.2192 & 2.1156 & 4.4036 & 2.5433 \\
\hline & 1.0252 & 1.3841 & 1.2197 & 2.1163 & 4.4044 & 2.5414 \\
\hline & 1.0252 & 1.3844 & 1.2194 & 2.1341 & 4.4239 & 2.5562 \\
\hline & 1.0244 & 1.3857 & 1.2181 & 2.1984 & 4.5012 & 2.5973 \\
\hline & 1.0223 & 1.3914 & 1.2136 & & & \\
\hline 8 & 1.0154 & 1.3939 & 1.2117 & 2.1771 & 4.4786 & 2.6246 \\
\hline & 1.0219 & 1.3865 & 1.2176 & 2.1244 & 4.4180 & 2.5577 \\
\hline & 1.0246 & 1.3845 & 1.2194 & 2.1115 & 4.3990 & 2.5394 \\
\hline & 1.0255 & 1.3838 & 1.2200 & 2.1078 & 4.3946 & 2.5332 \\
\hline & 1.0257 & 1.3838 & 1.2200 & 2.1135 & 4.3999 & 2.5376 \\
\hline & 1.0255 & 1.3842 & 1.2196 & 2.1308 & 4.4215 & 2.5518 \\
\hline & 1.0246 & 1.3856 & 1.2182 & 2.1989 & 4.4994 & 2.5967 \\
\hline & 1.0223 & 1.3913 & 1.2137 & & & \\
\hline 9 & 1.0154 & 1.3939 & 1.2117 & 2.1765 & 4.4779 & 2.6240 \\
\hline & 1.0220 & 1.3864 & 1.2177 & 2.1233 & 4.4167 & 2.5566 \\
\hline & 1.0246 & 1.3844 & 1.2195 & 2.1094 & 4.3966 & 2.5373 \\
\hline & 1.0256 & 1.3837 & 1.2202 & 2.1038 & 4.3900 & 2.5294 \\
\hline & 1.0260 & 1.3835 & 1.2203 & 2.1051 & 4.3902 & 2.5297 \\
\hline & 1.0260 & 1.3836 & 1.2202 & 2.1103 & 4.3978 & 2.5340 \\
\hline & 1.0256 & 1.3841 & 1.2197 & 2.1313 & 4.4205 & 2.5527 \\
\hline & 1.0246 & 1.3855 & 1.2182 & 2.1978 & 4.4997 & 2.5964 \\
\hline & 1.0224 & 1.3913 & 1.2137 & & & \\
\hline 10 & 1.0156 & 1.3938 & 1.2119 & 2.1769 & 4.4775 & 2.6229 \\
\hline & 1.0220 & 1.3864 & 1.2177 & 2.1237 & 4.4158 & 2.5564 \\
\hline & 1.0247 & 1.3843 & 1.2196 & 2.1083 & 4.3950 & 2.5358 \\
\hline & 1.0257 & 1.3836 & 1.2203 & 2.1007 & 4.3873 & 2.5260 \\
\hline & 1.0261 & 1.3833 & 1.2205 & 2.1010 & 4.3854 & 2.5255 \\
\hline & 1.0262 & 1.3833 & 1.2205 & 2.1023 & 4.3878 & 2.5264 \\
\hline & 1.0261 & 1.3835 & 1.2203 & 2.1106 & 4.3963 & 2.5343 \\
\hline & 1.0257 & 1.3840 & 1.2198 & 2.1285 & 4.4194 & 2.5508 \\
\hline & 1.0247 & 1.3855 & 1.2183 & 2.1972 & 4.4992 & 2.5957 \\
\hline & 1.0224 & 1.3913 & 1.2138 & & & \\
\hline 11 & 1.0154 & 1.3937 & 1.2119 & 2.1772 & 4.4772 & 2.6243 \\
\hline & 1.0220 & 1.3864 & 1.2178 & 2.1234 & 4.4154 & 2.5565 \\
\hline & 1.0247 & 1.3843 & 1.2196 & 2.1077 & 4.3943 & 2.5353 \\
\hline & 1.0257 & 1.3835 & 1.2203 & 2.1005 & 4.3859 & 2.5258 \\
\hline & 1.0262 & 1.3832 & 1.2206 & 2.0998 & 4.3829 & 2.5242 \\
\hline & 1.0263 & 1.3831 & 1.2207 & 2.0985 & 4.3830 & 2.5224 \\
\hline & 1.0263 & 1.3832 & 1.2206 & 2.1023 & 4.3864 & 2.5260 \\
\hline & 1.0262 & 1.3834 & 1.2204 & 2.1093 & 4.3955 & 2.5327 \\
\hline & 1.0257 & 1.3840 & 1.2198 & 2.1308 & 4.4189 & 2.5530 \\
\hline & 1.0247 & 1.3855 & 1.2183 & 2.1966 & 4.4989 & 2.5951 \\
\hline & 1.0224 & 1.3912 & 1.2138 & & & \\
\hline 12 & 1.0155 & 1.3938 & 1.2118 & 2.1750 & 4.4769 & 2.6223 \\
\hline & 1.0220 & 1.3864 & 1.2178 & 2.1248 & 4.4150 & 2.5584 \\
\hline & 1.0247 & 1.3843 & 1.2196 & 2.1063 & 4.3939 & 2.5340 \\
\hline & 1.0258 & 1.3835 & 1.2203 & 2.1010 & 4.3852 & 2.5264 \\
\hline & 1.0262 & 1.3832 & 1.2207 & 2.0969 & 4.3816 & 2.5211 \\
\hline & 1.0264 & 1.3830 & 1.2208 & 2.0985 & 4.3805 & 2.5224 \\
\hline & 1.0265 & 1.3830 & 1.2208 & 2.0973 & 4.3817 & 2.5207 \\
\hline & 1.0264 & 1.3831 & 1.2207 & 2.1020 & 4.3857 & 2.5256 \\
\hline & 1.0262 & 1.3834 & 1.2204 & 2.1088 & 4.3951 & 2.5320 \\
\hline & 1.0258 & 1.3839 & 1.2198 & 2.1311 & 4.4186 & 2.5531 \\
\hline & 1.0248 & 1.3854 & 1.2183 & 2.1964 & 4.4987 & 2.5947 \\
\hline & 1.0224 & 1.3912 & 1.2138 & & & \\
\hline
\end{tabular}


TABLE V. Bond lengths $(\AA)$ associated with the strongest H-bond interactions in the $(d f a)_{n}$ clusters $(n=2-12)$.

\begin{tabular}{cccccc}
\hline \hline$n$ & $r(\mathrm{~N}-\mathrm{H})$ & $r(\mathrm{C}-\mathrm{N})$ & $r(\mathrm{C}=\mathrm{O})$ & $r(\mathrm{O} \cdots \mathrm{H}-\mathrm{N})$ & $r(\mathrm{~N} \cdots \mathrm{N})$ \\
\hline 2 & 1.0191 & 1.3941 & 1.2109 & 2.2785 & 4.5937 \\
3 & 1.0206 & 1.3889 & 1.2151 & 2.2120 & 4.5180 \\
4 & 1.0229 & 1.3870 & 1.2169 & 2.1585 & 4.4562 \\
5 & 1.0238 & 1.3855 & 1.2183 & 2.1407 & 4.4338 \\
6 & 1.0248 & 1.3847 & 1.2191 & 2.1239 & 4.4128 \\
7 & 1.0252 & 1.3841 & 1.2197 & 2.1156 & 4.4036 \\
8 & 1.0257 & 1.3838 & 1.2200 & 2.1078 & 4.3946 \\
9 & 1.0260 & 1.3835 & 1.2203 & 2.1038 & 4.3900 \\
10 & 1.0261 & 1.3833 & 1.2205 & 2.1007 & 4.3873 \\
11 & 1.0263 & 1.3832 & 1.2206 & 2.0985 & 4.3830 \\
12 & 1.0264 & 1.3831 & 1.2207 & 2.0973 & 4.3817 \\
\hline \hline
\end{tabular}

involved in the strongest hydrogen bonding interaction for each cluster. Trends in the elongation of $r(\mathrm{~N}-\mathrm{H})$ and $r(\mathrm{C}=\mathrm{O})$, and in the reduction of $r(\mathrm{C}-\mathrm{N})$ with increasing chain length can be appreciated by plotting the shifts of the bond lengths (Fig. 4), relative to those in the dimer, versus $1 / n$, where $n$ is the number of molecules in the cluster; a perfect linear correlation is found in all cases. Extrapolations to $n=\infty$ lead to the following approximate asymptotic values for the infinitely extended polymer: $r(\mathrm{C}-\mathrm{N})=1.381 \AA$, $r(\mathrm{C}=\mathrm{O})=1.228 \AA$, and $r(\mathrm{~N}-\mathrm{H})=1.029 \AA$. These changes correspond to an overall $r(\mathrm{C}-\mathrm{N})$ reduction, in going from dimer to infinite polymer, of about $0.013 \AA$, and an overall increase in $r(\mathrm{C}=\mathrm{O})$ and $r(\mathrm{~N}-\mathrm{H})$ of about $0.017 \AA$, and $0.010 \AA$, respectively.

Intermolecular geometrical parameters are also notably altered by the cooperative nature of the hydrogen bond. Table IV displays the intermolecular distances $r(\mathrm{O} \cdots \mathrm{H}-\mathrm{N})$, $r(\mathrm{~N} \cdots \mathrm{N})$, and $r(\mathrm{O} \cdots \mathrm{H}-\mathrm{C})$ for all clusters. It is seen that adding a third molecule reduces considerably both $r(\mathrm{O} \cdots \mathrm{H}-\mathrm{N})$ and $r(\mathrm{~N} \cdots \mathrm{N})$. The $r(\mathrm{O} \cdots \mathrm{H}-\mathrm{N})$ distances for the interaction of the rightmost molecule with the central molecule are decreased by $0.067 \AA$ compared with those in the dimer. The interaction of the leftmost molecule with the central molecule exhibits a reduction of $0.054 \AA$. The $r(\mathrm{~N} \cdots \mathrm{N})$ distances are also reduced by 0.076 , and $0.061 \AA$, respectively; the shrinkage of these distances continues

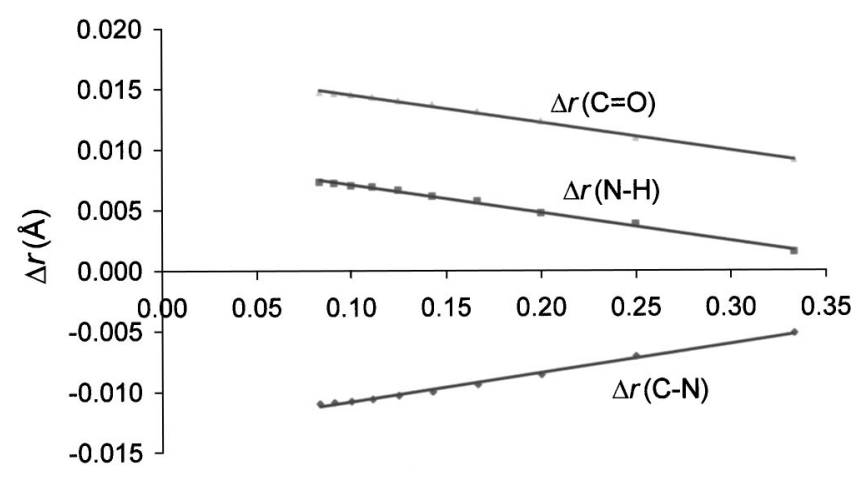

$1 / n$

FIG. 4. Trends in the shifts, relative to dimer, of $r(\mathrm{~N}-\mathrm{H}), r(\mathrm{C}=\mathrm{O})$, and $r(\mathrm{C}-\mathrm{N})$ vs $1 / n$, where $n$ is the number of molecules in the cluster. The following correlations are found: $\Delta r(\mathrm{~N}-\mathrm{H})=-0.0231(1 / n)-0.0094$; $\Delta r(\mathrm{C}=\mathrm{O})=-0.0231(1 / n)+0.0168 ; \Delta r(\mathrm{C}-\mathrm{N})=0.0238(1 / n)-0.0132$.

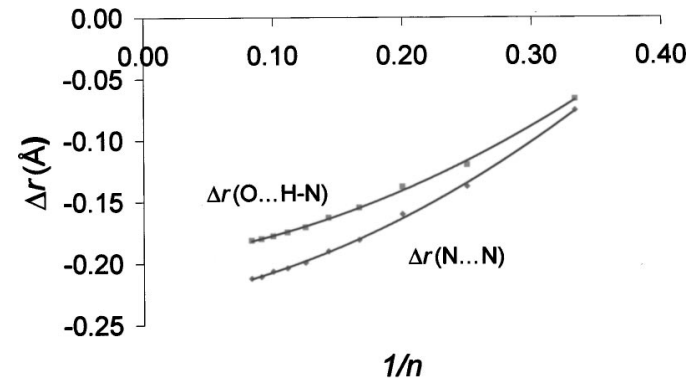

FIG. 5. Trends in the shifts, relative to dimer, of $r(\mathrm{O} \cdots \mathrm{H}-\mathrm{N})$, and $r(\mathrm{~N} \cdots \mathrm{N})$ vs $1 / n$, where $n$ is the number of molecules in the cluster. The following correlations are found: $\Delta r(\mathrm{O} \cdots \mathrm{H}-\mathrm{N})=0.806(1 / n)^{2}$ $+0.122(1 / n)-0.198 ; \Delta r(\mathrm{~N} \cdots \mathrm{N})=0.935(1 / n)^{2}+0.155(1 / n)-0.232$.

for higher $n$. The hydrogen bond distances $r(\mathrm{O} \cdots \mathrm{H}-\mathrm{N})$ for the two rightmost molecules goes from a value of $0.279 \AA$ in the dimer to $2.175 \AA$ in the dodecamer. This is a reduction of over $0.10 \AA$. A similar contraction is observed for the $r(\mathrm{~N} \cdots \mathrm{N})$ bond distance. The corresponding contractions for the two leftmost molecules are slightly smaller.

The intermolecular geometry changes are more prominent for the interior molecules reflecting the influence of strong cooperative effects. Table $\mathrm{V}$ shows the intermolecular parameters $r(\mathrm{O} \cdots \mathrm{H}-\mathrm{N})$, and $r(\mathrm{~N} \cdots \mathrm{N})$ for the interior molecules associated with the strongest interaction for a given $n$. Cooperativity effects give rise to significant reductions in both parameters for the trimer relative to dimer $(\sim 0.076 \AA)$, and for the tetramer relative to trimer $(\sim 0.067 \AA)$. Further appreciable reductions are still seen for the larger clusters. The trends in these parameters upon enlarging the cluster size can be illustrated by plotting their changes $[\Delta r(\mathrm{O} \cdots \mathrm{H}-\mathrm{N})$, and $\Delta r(\mathrm{~N} \cdots \mathrm{N})]$, with the dimer as a reference system, versus $1 / n$, where $n$ is the number of molecules. Figure 5 shows that the relative intermolecular reductions as a function of $1 / n$ can be perfectly expressed in terms of simple quadratic polynomial equations. The quadratic correlations lead to an eventual $r(\mathrm{~N} \cdots \mathrm{N})$ contraction of about $0.23 \AA$, and an $r(\mathrm{O} \cdots \mathrm{H}-\mathrm{N})$ contraction of about $0.20 \AA$ for $n=\infty$. These asymptotic intermolecular contractions more than triple those found for $n=3$.

Based on the asymptotic contractions, a sufficiently large cluster is expected to have $r(\mathrm{~N} \cdots \mathrm{N})$ and $r(\mathrm{O} \cdots \mathrm{H}-\mathrm{N})$ intermolecular bond distances that are respectively $6 \%$ and $9 \%$ shorter than those expected from a noncooperative model based on the dimer geometry. These impressive changes reflect the ability of H-bond cooperativity to strengthen attractive forces so as to overcome steric and electrostatic repulsions expected from bringing several atoms, namely nitrogen and oxygen atoms, much closer to one another.

Table IV shows a rather interesting contraction of the $r(\mathrm{O} \cdots \mathrm{H}-\mathrm{C})$ distance as the chain grows. For instance, a reduction of up to $0.07 \AA$ is found in the trimer. The contraction is more than twice in the dodecamer $(\sim 0.18 \AA)$. This significant decrease in $r(\mathrm{O} \cdots \mathrm{H}-\mathrm{C})$ suggests that a secondary hydrogen bond interaction is taking place between each carbonyl oxygen atom of a diformamide molecule and a hydrogen atom attached to the carbonyl carbon of the next molecule as shown in Fig. 6. This secondary interaction provides 


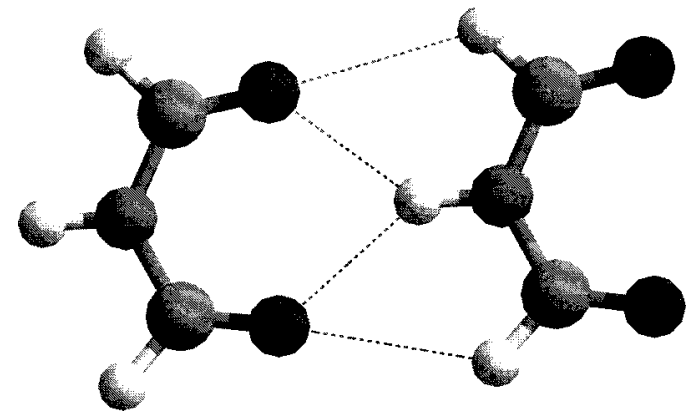

FIG. 6. Schematic structure showing a secondary hydrogen-bond interaction between each carbonyl oxygen atom of a diformamide molecule and a hydrogen atom attached to the carbonyl carbon of an adjacent molecule.

additional stability to the chain. The cluster can be viewed, therefore, as having a bifurcated $\mathrm{H}$-bonding interaction between the amide hydrogen $(\mathrm{H}-\mathrm{N})$ of one molecule and the carbonyl oxygen atoms of the next molecule (usually termed bifurcated donor), and as having a secondary bifurcated hydrogen bonding interactions between the carbonyl oxygen atoms, the hydrogen atom from the amide group $(\mathrm{H}-\mathrm{N})$ and the hydrogen atoms from the carbonyl carbons (bifurcated acceptor).

Dipole moments. Cooperative effects in the chain are expected to result in a sizeable enhancement of the dipole moment of the cluster. That is, the dipole moment of the cluster should be larger than the vector sum of the individual dipole moments of the isolated monomers. Table VI shows that this is indeed the case. The dipole moment per molecule in the chain, $\mu_{n} / n$, is enhanced by about $17 \%$ in the dimer and up to $40 \%$ in the dodecamer (from 6.68 to $9.35 \mathrm{D}$ ). In other words, the dipole moment of the dodecamer is about 32 $\mathrm{D}$ greater than would be expected from an additive dipole model. This result is echoed by the dipole cooperativity factor, measured in a manner similar to that for energies and shown in the fourth column of Table VI. The calculated dipole cooperativity for the largest cluster $(2.91 \mathrm{D})$ is enhanced by about $57 \%$ with respect to that in the dimer $(1.85 \mathrm{D})$. Another way to appreciate the enhancement of the dipole

TABLE VI. HF/6-31+ $\mathrm{G}(d)$ dipole moments (Debyes) in linear chainlike $(d f a)_{n}$ clusters.

\begin{tabular}{ccccc}
\hline \hline$n$ & $\mu_{n}$ & $\mu / n$ & Cooperativity $^{\mathrm{a}}$ & $\mu_{n}-\mu_{n-1}-\mu_{1}$ \\
\hline 1 & 6.68 & 6.68 & & \\
2 & 15.21 & 7.61 & 1.85 & 1.85 \\
3 & 24.42 & 8.14 & 2.19 & 2.53 \\
4 & 33.92 & 8.48 & 2.40 & 2.82 \\
5 & 43.57 & 8.71 & 2.54 & 2.97 \\
6 & 53.30 & 8.88 & 2.64 & 3.05 \\
7 & 63.07 & 9.01 & 2.72 & 3.09 \\
8 & 72.87 & 9.11 & 2.78 & 3.12 \\
9 & 82.69 & 9.19 & 2.82 & 3.14 \\
10 & 92.53 & 9.25 & 2.86 & 3.16 \\
11 & 102.37 & 9.31 & 2.89 & 3.16 \\
12 & 112.22 & 9.35 & 2.91 & 3.17 \\
\hline \hline
\end{tabular}

aipole cooperativity defined as $\left.\left[\mu_{n}-n \mu_{1}\right] /(n-1)\right]$, where $\mu_{n}$ is the cluster dipole moment.

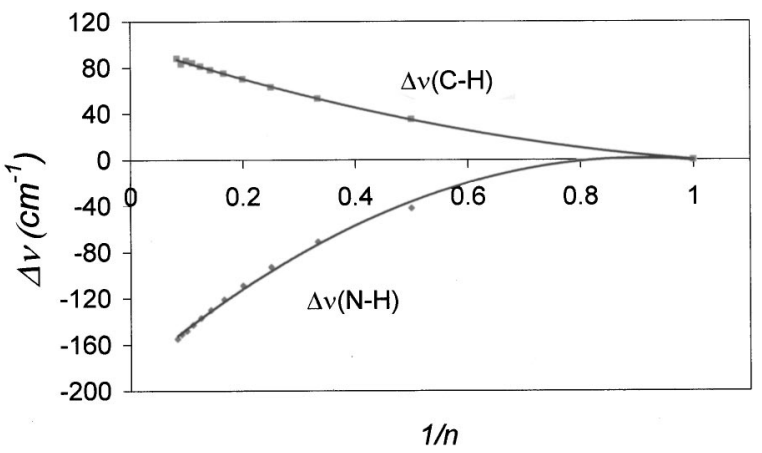

FIG. 7. Plots of stretching $\nu(\mathrm{N}-\mathrm{H})$ and $\nu(\mathrm{C}-\mathrm{H})$ shifts vs $1 / n$, where $n$ is the number of molecules. The following correlations are found: $\Delta \nu(\mathrm{N}-\mathrm{H})$ $=-248(1 / n)^{2}+452(1 / n)-205 ; \Delta \nu(\mathrm{C}-\mathrm{H})=56(1 / n)^{2}-178(1 / n)+122$.

moment is by looking at the series $\mu_{n}-\mu_{n-1}-\mu_{1}$. This term goes from $1.85 \mathrm{D}$ in the dimer to $3.17 \mathrm{D}$ in the dodecamer.

Harmonic stretching frequencies and intensities. Vibrational frequency shifts are commonly used to gauge the cooperative nature of $\mathrm{H}$-bonding interactions. Upon $\mathrm{H}$-bond formation, the $\mathrm{N}-\mathrm{H}$ stretching frequency shifts to lower frequencies, and its intensity increases. The extent to which these changes are actually observable depends on the strength of the hydrogen bond. Cooperative effects strengthen the hydrogen-bond interaction and therefore give rise to considerable frequency shifts and intensity changes. The calculated harmonic $\mathrm{N}-\mathrm{H}$ stretching frequencies as well as their intensification ratios are listed in Table VII. Another mode of vibration that is expected to vary upon formation of secondary hydrogen bonding is the $\mathrm{C}-\mathrm{H}$ stretching mode. The symmetric $\mathrm{C}-\mathrm{H}$ stretching modes are also listed in Table VII.

With respect to the $\mathrm{N}-\mathrm{H}$ stretches, there exists a spread of frequencies and intensities that depends on the size of the cluster. For any given cluster, the highest $\nu(\mathrm{N}-\mathrm{H})$ frequency corresponds to the stretching of the free $\mathrm{N}-\mathrm{H}$ bond. In the dimer, the lower frequency corresponds to the $\mathrm{N}-\mathrm{H}$ bond participating in the hydrogen bond. For any other cluster, the frequencies are not so clearly identified with any particular molecule. A given $\mathrm{N}-\mathrm{H}$ stretching frequency is rather associated with a collective motion of two or more $\mathrm{N}-\mathrm{H}$ bonds. It should be said that not all $\mathrm{N}-\mathrm{H}$ bonds are stretched to the same extent, or in the same direction. This helps explain the oscillating intensities of the $\nu(\mathrm{N}-\mathrm{H})$ frequencies shown in Table VII. The most intense frequency in a cluster corresponds to the symmetric collective $\mathrm{N}-\mathrm{H}$ stretching mode, i.e., $\mathrm{N}-\mathrm{H}$ bonds stretched in the same direction and with two or more $\mathrm{N}-\mathrm{H}$ bonds stretched to about the same extent. The intensity of this symmetric collective mode is increased with cluster size. This can be qualitatively rationalized in terms of the intermolecular charge transfer and associated dipole derivative. In a symmetric collective $\mathrm{N}-\mathrm{H}$ stretching mode, the net overall effect will be to shift charge from one end of the chain to the other. This spatial charge displacement (and consequently the dipole moment derivative) grows cooperatively with the size of the cluster, resulting in an $n$-dependent intensity increase. On the other hand, a collective $\nu(\mathrm{N}-\mathrm{H})$ 
TABLE VII. Calculated harmonic stretching frequencies of $(d f a)_{n}$ clusters at B3LYP/6-31+ $\mathrm{G}(d)$ level.

\begin{tabular}{|c|c|c|c|c|c|c|}
\hline \multirow[b]{2}{*}{$n$} & \multicolumn{3}{|c|}{$\mathrm{N}-\mathrm{H}$ stretching } & \multicolumn{3}{|c|}{$\mathrm{C}-\mathrm{H}$ stretching } \\
\hline & $\nu\left(\mathrm{cm}^{-1}\right)$ & $\Delta \nu\left(\mathrm{cm}^{-1}\right)$ & $A_{n} / A_{1}$ & $\nu\left(\mathrm{cm}^{-1}\right)$ & $\Delta \nu\left(\mathrm{cm}^{-1}\right)$ & $A_{n} / A_{1}$ \\
\hline 1 & 3577 & 0 & 1 & 2977 & 0 & 1.0 \\
\hline \multirow[t]{2}{*}{2} & 3577 & 0 & 2 & 3017 & 40 & 0.9 \\
\hline & 3530 & -47 & 13 & 3007 & 30 & 0.9 \\
\hline \multirow[t]{3}{*}{3} & 3577 & 0 & 2 & 3049 & 72 & 0.7 \\
\hline & 3509 & -68 & 9 & 3028 & 51 & 0.9 \\
\hline & 3501 & -76 & 30 & 3016 & 39 & 0.7 \\
\hline \multirow[t]{4}{*}{4} & 3577 & 0 & 2 & 3060 & 83 & 0.6 \\
\hline & 3499 & -78 & 15 & 3057 & 80 & 0.7 \\
\hline & 3491 & -86 & 14 & 3032 & 55 & 0.9 \\
\hline & 3472 & -105 & 42 & 3019 & 42 & 0.7 \\
\hline 5 & 3576 & -1 & 2 & 3068 & 91 & 0.5 \\
\hline & 3494 & -83 & 17 & 3064 & 87 & 0.7 \\
\hline & 3486 & -91 & 15 & 3060 & 83 & 0.6 \\
\hline & 3463 & -114 & 0 & 3034 & 57 & 0.9 \\
\hline & 3455 & -122 & 73 & 3021 & 44 & 0.7 \\
\hline 6 & 3576 & -1 & 2 & 3072 & 95 & 0.5 \\
\hline & 3491 & -86 & 18 & 3072 & 95 & 0.6 \\
\hline & 3483 & -94 & 16 & 3066 & 89 & 0.7 \\
\hline & 3455 & -122 & 18 & 3062 & 85 & 0.6 \\
\hline & 3454 & -123 & 4 & 3035 & 58 & 0.9 \\
\hline & 3441 & -136 & 89 & 3022 & 45 & 0.7 \\
\hline 7 & 3578 & 1 & 2 & 3075 & 98 & 0.5 \\
\hline & 3490 & -87 & 19 & 3074 & 97 & 0.5 \\
\hline & 3482 & -95 & 16 & 3073 & 96 & 0.6 \\
\hline & 3451 & -126 & 14 & 3067 & 90 & 0.7 \\
\hline & 3450 & -127 & 20 & 3063 & 86 & 0.6 \\
\hline & 3441 & -136 & 0 & 3035 & 58 & 0.9 \\
\hline & 3431 & -146 & 116 & 3022 & 45 & 0.7 \\
\hline 8 & 3578 & 1 & 2 & 3078 & 101 & 0.4 \\
\hline & 3489 & -88 & 19 & 3077 & 100 & 0.6 \\
\hline & 3481 & -96 & 16 & 3075 & 98 & 0.6 \\
\hline & 3449 & -128 & 17 & 3074 & 97 & 0.6 \\
\hline & 3448 & -129 & 20 & 3067 & 90 & 0.7 \\
\hline & 3437 & -140 & 14 & 3063 & 86 & 0.6 \\
\hline & 3434 & -143 & 0 & 3035 & 58 & 0.9 \\
\hline & 3424 & -153 & 139 & 3022 & 45 & 0.7 \\
\hline 9 & 3578 & 1 & 2 & 3079 & 102 & 0.4 \\
\hline & 3489 & -88 & 19 & 3079 & 102 & 0.4 \\
\hline & 3481 & -96 & 16 & 3078 & 101 & 0.6 \\
\hline & 3448 & -129 & 18 & 3076 & 99 & 0.6 \\
\hline & 3447 & -130 & 20 & 3074 & 97 & 0.6 \\
\hline & 3434 & -143 & 0 & 3068 & 91 & 0.7 \\
\hline & 3433 & -144 & 28 & 3064 & 87 & 0.6 \\
\hline & 3427 & -150 & 0 & 3036 & 59 & 0.9 \\
\hline & 3418 & -159 & 164 & 3022 & 45 & 0.7 \\
\hline 10 & 3576 & -1 & 2 & 3080 & 103 & 0.3 \\
\hline & 3488 & -89 & 19 & 3080 & 103 & 0.5 \\
\hline & 3480 & -97 & 16 & 3079 & 102 & 0.6 \\
\hline & 3447 & -130 & 19 & 3079 & 102 & 0.6 \\
\hline & 3446 & -131 & 19 & 3076 & 99 & 0.6 \\
\hline & 3432 & -145 & 18 & 3075 & 98 & 0.6 \\
\hline & 3432 & -145 & 3 & 3068 & 91 & 0.7 \\
\hline & 3427 & -150 & 23 & 3064 & 87 & 0.6 \\
\hline & 3423 & -154 & 0 & 3035 & 58 & 0.9 \\
\hline & 3414 & -163 & 189 & 3023 & 46 & 0.7 \\
\hline 11 & 3579 & 2 & 2 & 3081 & 104 & 0.3 \\
\hline & 3488 & -89 & 19 & 3081 & 104 & 0.3 \\
\hline & 3480 & -97 & 16 & 3080 & 103 & 0.7 \\
\hline & 3447 & -130 & 20 & 3079 & 102 & 0.6 \\
\hline & 3446 & -131 & 19 & 3077 & 100 & 0.6 \\
\hline & 3431 & -146 & 11 & 3075 & 98 & 0.6 \\
\hline & 3431 & -146 & 16 & 3069 & 92 & 0.6 \\
\hline & 3426 & -151 & 0 & 3064 & 87 & 0.7 \\
\hline & 3424 & -153 & 34 & 3036 & 59 & 0.6 \\
\hline & 3418 & -159 & 0 & 3033 & 56 & 0.9 \\
\hline & 3411 & -166 & 214 & 3022 & 45 & 0.7 \\
\hline 12 & 3578 & 1 & 2 & 3081 & 104 & 0.1 \\
\hline & 3488 & -89 & 20 & 3081 & 104 & 0.5 \\
\hline & 3480 & -97 & 16 & 3081 & 104 & 0.5 \\
\hline & 3446 & -131 & 20 & 3081 & 104 & 0.6 \\
\hline & 3445 & -132 & 19 & 3080 & 103 & 0.6 \\
\hline & 3431 & -146 & 13 & 3079 & 102 & 0.6 \\
\hline & 3431 & -146 & 14 & 3076 & 99 & 0.6 \\
\hline & 3425 & -152 & 10 & 3075 & 98 & 0.6 \\
\hline & 3424 & -153 & 0 & 3068 & 91 & 0.7 \\
\hline & 3421 & -156 & 41 & 3064 & 87 & 0.6 \\
\hline & 3415 & -162 & 0 & 3036 & 59 & 0.9 \\
\hline & 3408 & -169 & 256 & 3023 & 46 & 0.7 \\
\hline
\end{tabular}

cluster mode with $\mathrm{N}-\mathrm{H}$ bonds stretched in opposite directions tend to have much lower intensity because of cancellation effects that result in a much smaller, if any, net displacement of charge. In fact, the intensity is reduced to zero in a cluster mode where half of the $\mathrm{N}-\mathrm{H}$ bonds involved in the collective motion are moving in one direction, and the other half is moving in the opposite direction.

Table VII shows that the free $\mathrm{N}-\mathrm{H}$ bond frequency remains essentially unchanged whereas those of the more interior $\mathrm{N}-\mathrm{H}$ bonds present sizeable shifts to lower frequencies. The redshift of the most intense mode varies from $47 \mathrm{~cm}^{-1}$ in the dimer to $169 \mathrm{~cm}^{-1}$ in the dodecamer. Similarly, the intensification ratio for the most intense band goes from 13 in the dimer to 256 in the dodecamer. That is, the intensification ratio is enhanced with respect to dimer by a factor of about 20 in the largest cluster considered.

With respect to the $\mathrm{C}-\mathrm{H}$ stretches, there is a spread of frequencies each distinctively identified with a single molecule in the cluster. This is in contrast to the $\mathrm{N}-\mathrm{H}$ stretches where each mode is the result of a collective motion of $\mathrm{N}-\mathrm{H}$ bonds. Since each $\mathrm{C}-\mathrm{H}$ frequency involves just one molecule, the intensity of the mode will depend mainly on the strength of the $\mathrm{C}-\mathrm{H} \cdots \mathrm{O}$ interaction and not on whether a collective motion of $\mathrm{C}-\mathrm{H}$ bonds will result in a net change of dipole moment. As $n$ increases, the $\mathrm{C}-\mathrm{H}$ stretching modes are shifted upward and their intensities are somewhat reduced as shown in Table VII. For all clusters, the two lowest frequencies correspond to the free, non-H-bonded molecule and to the H-bonded terminal molecule, with the frequency of the free edge being a little higher. Insertion of additional molecules in the center of an already formed chain shifts these two frequencies to the blue. The converged $\nu(\mathrm{C}-\mathrm{H})$ of the free end molecule $\left(3036 \mathrm{~cm}^{-1}\right)$ has a blueshift of 59 $\mathrm{cm}^{-1}$. The corresponding blueshift of the H-bonded edge amounts to $46 \mathrm{~cm}^{-1}$. Neither frequency shows significant reduction in intensity. The first $\nu(\mathrm{C}-\mathrm{H})$ frequency listed in Table VII corresponds to the interior molecules associated with the strongest H-bond interaction. This is the most blueshifted frequency and also the one whose intensity is progressively reduced the most. This frequency reaches convergence at about $3081 \mathrm{~cm}^{-1}$. This represents a blueshift of 104 $\mathrm{cm}^{-1}$ which is appreciably higher than in either terminal molecule.

The lowest $\nu(\mathrm{N}-\mathrm{H})$ and highest $\nu(\mathrm{C}-\mathrm{H})$ stretching frequencies as a function of cluster size are displayed in Fig. 7. It is seen that the $\nu(\mathrm{N}-\mathrm{H})$ and $\nu(\mathrm{C}-\mathrm{H})$ shifts can be expressed in terms of quadratic polynomial equations. These equations lead to an asymptotic redshift of about $205 \mathrm{~cm}^{-1}$ for $\nu(\mathrm{N}-\mathrm{H})$, and an asymptotic blueshift of about $122 \mathrm{~cm}^{-1}$ for $\nu(\mathrm{C}-\mathrm{H})$.

Average dissociation energies and frequency shifts. Figure 8 is a graph of shifts per bifurcated $\mathrm{H}$ bond of the of the lowest $\nu(\mathrm{N}-\mathrm{H})$ and highest $\nu(\mathrm{C}-H)$ versus the average dissociation energy. It is seen that the frequency shifts and $D_{e} /(n-1)$ are best fit by quadratic correlations. What is interesting about these correlations is that we can get estimates for the average dissociation energy in the limit of $n$ $=\infty$. For sufficiently large $n$, the nonadditive character of the hydrogen-bond interaction is expected to show saturation 


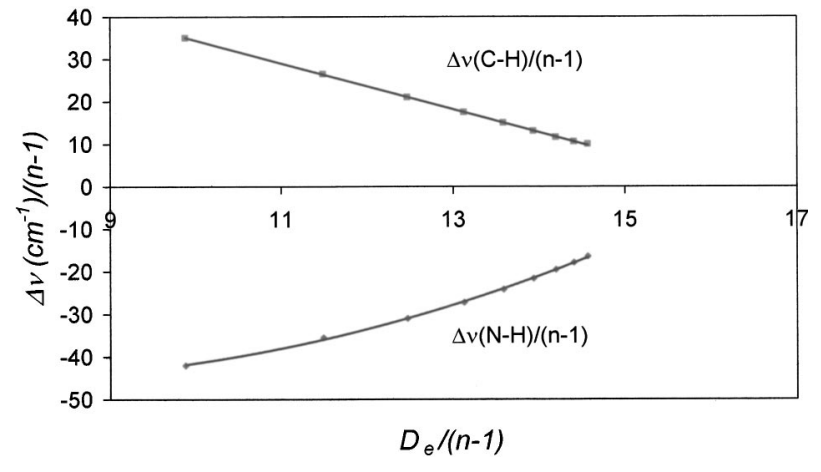

FIG. 8. Plot of the shifts per bifurcated $\mathrm{H}$ bond of the average shift of the lowest $\nu(\mathrm{N}-\mathrm{H})$ and $\nu(\mathrm{C}-\mathrm{H})$ stretching frequencies vs average dissociation energy, $D_{e} /(n-1)$. The following correlations are found: $\Delta \nu(\mathrm{N}-\mathrm{H})=0.58\left(D_{e} /(n-1)\right)^{2}-8.31 D_{e} /(n-1)-21.10 ; \quad \Delta \nu(\mathrm{C}-\mathrm{H})$ $=-0.74\left(D_{e} /(n-1)\right)^{2}+11.83\left(D_{e} /(n-1)\right)-3.66$.

which will result in negligible, if any, average frequency shifts for $n=\infty$. In principle, we should get the same value regardless of which correlation is used. The quadratic correlation from $\nu(\mathrm{C}-\mathrm{H})$ shifts predicts a limiting $D_{e} /(n-1)$ $=15.67 \mathrm{kcal} / \mathrm{mol}$, and the quadratic correlation from $\nu(\mathrm{N}-\mathrm{H})$ shifts predicts a limiting value of $D_{e} /(n-1)$ $=16.52 \mathrm{kcal} / \mathrm{mol}$. The so estimated average dissociation energies are in very good agreement with the value of 15.62 $\mathrm{kcal} / \mathrm{mol}$ obtained from the relationship between $D_{e} /(n$ -1 ) and $1 / n$ (Fig. 2).

${ }^{1} H$-NMR shielding constants. Another spectroscopic technique that has shown great potential in investigating the presence and strength of a $\mathrm{H}$ bond is nuclear magnetic resonance (NMR). The calculated average isotropic shielding constants of the $\mathrm{N}-\mathrm{H}$ and $\mathrm{C}-\mathrm{H}$ protons as well as their chemical shifts $\left(\sigma\left({ }^{1} \mathrm{H}\right)_{\text {monomer }}-\sigma\left({ }^{1} \mathrm{H}\right)_{\text {cluster }}\right)$ are reported in Table VIII. The trends in the NMR $\sigma\left({ }^{1} \mathrm{H}\right)$ shielding constants as a function of cluster size are illustrated in Fig. 9 by plotting the computed average isotropic shielding constants of both $\mathrm{N}-\mathrm{H}$ and $\mathrm{C}-\mathrm{H}$ protons involved in hydrogen bonding versus $1 / n$, where $n$ is the number of molecules in the cluster. A perfect linear correlation is found for both types of protons. The linear correlation in the $\mathrm{N}-\mathrm{H}$ case leads to an asymptotic $\sigma\left({ }^{1} \mathrm{H}\right)$ value of $19.69 \mathrm{ppm}$, which represents a downfield chemical shift relative to the monomer of 5.39

TABLE VIII. Average ${ }^{1} \mathrm{H}-\mathrm{NMR}$ isotropic chemical shielding constants $(\mathrm{ppm})$ and corresponding chemical shifts of $(d f a)_{n}$ clusters.

\begin{tabular}{ccccc}
\hline \hline$n$ & ${ }^{1} \mathrm{H}-\mathrm{NMR}(\mathrm{N}-\mathrm{H})$ & $\sigma(\mathrm{N}-\mathrm{H})$ & ${ }^{1} \mathrm{H}-\mathrm{NMR}(\mathrm{C}-\mathrm{H})$ & $\sigma(\mathrm{C}-\mathrm{H})$ \\
\hline 1 & 25.08 & & 23.24 & \\
2 & 22.29 & 2.79 & 22.87 & 0.37 \\
3 & 21.55 & 3.53 & 22.80 & 0.44 \\
4 & 21.11 & 3.97 & 22.76 & 0.48 \\
5 & 20.82 & 4.26 & 22.72 & 0.52 \\
6 & 20.62 & 4.46 & 22.70 & 0.54 \\
7 & 20.47 & 4.61 & 22.68 & 0.56 \\
8 & 20.36 & 4.72 & 22.67 & 0.57 \\
9 & 20.27 & 4.81 & 22.66 & 0.58 \\
10 & 20.20 & 4.88 & 22.65 & 0.59 \\
11 & 20.14 & 4.94 & 22.65 & 0.59 \\
12 & 20.09 & 4.99 & 22.64 & 0.60 \\
\hline \hline
\end{tabular}

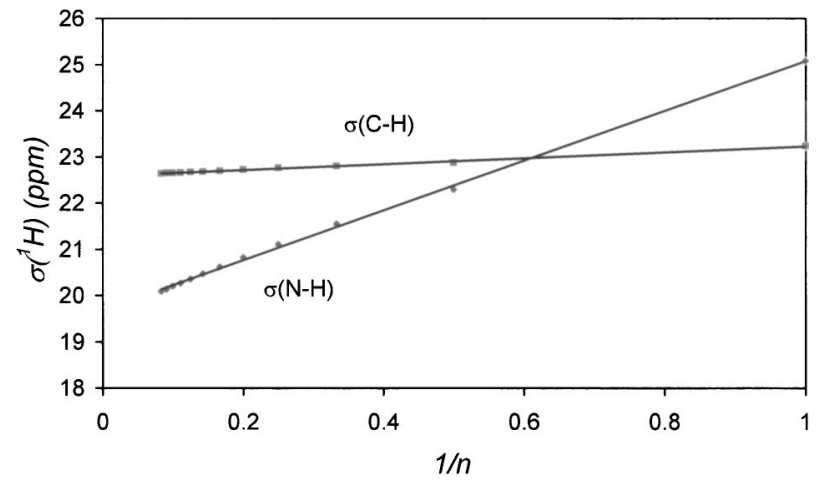

FIG. 9. Plot of the computed average isotropic shielding constants of both $\mathrm{N}-\mathrm{H}$ and $\mathrm{C}-\mathrm{H}$ protons involved in hydrogen bonding vs $1 / n$, where $n$ is the number of molecules in the cluster. The following correlations are found: $\sigma(\mathrm{N}-\mathrm{H})=5.39(1 / n)+19.69 ; \sigma(\mathrm{C}-\mathrm{H})=0.64(1 / n)+22.59$.

$\mathrm{ppm}$. In the $\mathrm{C}-\mathrm{H}$ case, the predicted asymptotic value for $\sigma\left({ }^{1} \mathrm{H}\right)$ is $22.59 \mathrm{ppm}$ corresponding to a downfield shift of just $0.65 \mathrm{ppm}$ in tandem with the much weaker character of the $\mathrm{C}-\mathrm{H}$...O interaction. Some authors have suggested a threshold for significance of $0.5 \mathrm{ppm}$ for two-center $\mathrm{C}-\mathrm{H}$...O interactions. ${ }^{38,39}$ Thus, a chemical shift between 0.40 and $0.65 \mathrm{ppm}$ seems reasonable for a $\mathrm{C}-\mathrm{H}$ proton interacting with an oxygen atom that is simultaneously having a relatively strong interaction with an $\mathrm{N}-\mathrm{H}$ proton.

Figure 10 presents a plot of the $\mathrm{N}-\mathrm{H}$ and $\mathrm{C}-\mathrm{H}$ proton chemical shifts as a function of the average interaction energies. Again, a perfect linear correlation is found for both the $\mathrm{N}-\mathrm{H}$ and $\mathrm{C}-\mathrm{H}$ chemical shifts. Use of the linear correlations found in Figs. 9 and 10 allows us to get an alternative estimate of the asymptotic limiting value of $D_{e} /(n-1)$. For example, using the extrapolated value for the $\mathrm{N}-\mathrm{H}$ chemical shift $(5.39 \mathrm{ppm})$ in the linear equation of Fig. 10, we get an asymptotic average energy of $15.71 \mathrm{kcal} / \mathrm{mol}$. Using data for the $\mathrm{C}-\mathrm{H}$ case, we get a value of $15.88 \mathrm{kcal} / \mathrm{mol}$. These values are remarkably close to each other and to the values obtained from extrapolations of Fig. $2(15.62 \mathrm{kcal} / \mathrm{mol})$ and Fig. $8(15.67 \mathrm{kcal} / \mathrm{mol}$, and $16.52 \mathrm{kcal} / \mathrm{mol})$.

Charge distributions: The extent of charge redistribution as a function of cluster size was investigated by calculating

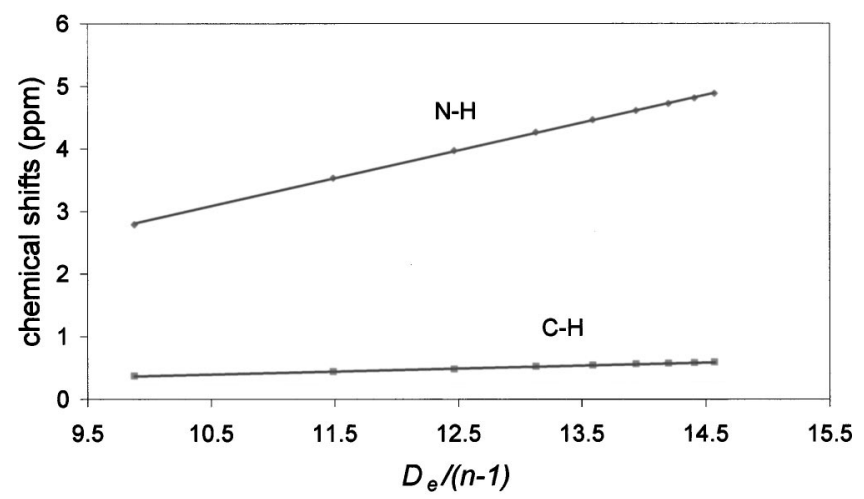

FIG. 10. Plot of the $\mathrm{N}-\mathrm{H}$ and $\mathrm{C}-\mathrm{H}$ proton chemical shifts as a function of the average interaction energies. The following correlations are found: $\sigma(\mathrm{N}-\mathrm{H})_{1}-\sigma(\mathrm{N}-\mathrm{H})_{n}=0.44 D_{e} /(n-1)-1.58 ; \quad \sigma(\mathrm{C}-\mathrm{H})_{1}-\sigma(\mathrm{C}-\mathrm{H})_{n}$ $=0.047 D_{e} /(n-1)-0.10$. 
TABLE IX. Calculated natural charges of each monomer in linear $(d f a)_{n}$ clusters.

\begin{tabular}{|c|c|c|c|c|c|c|c|c|c|c|c|c|}
\hline$n$ & 1 & 2 & 3 & 4 & 5 & 6 & 7 & 8 & 9 & 10 & 11 & 12 \\
\hline 1 & 0.0000 & & & & & & & & & & & \\
\hline 2 & 0.0120 & -0.0120 & & & & & & & & & & \\
\hline 3 & 0.0159 & -0.0004 & -0.0155 & & & & & & & & & \\
\hline 4 & 0.0173 & 0.0030 & -0.0036 & -0.0167 & & & & & & & & \\
\hline 5 & 0.0178 & 0.0040 & -0.0001 & -0.0046 & -0.0171 & & & & & & & \\
\hline 6 & 0.0181 & 0.0045 & 0.0010 & -0.0011 & -0.0050 & -0.0174 & & & & & & \\
\hline 7 & 0.0182 & 0.0047 & 0.0014 & -0.0001 & -0.0016 & -0.0052 & -0.0175 & & & & & \\
\hline 8 & 0.0183 & 0.0048 & 0.0016 & 0.0004 & -0.0005 & -0.0018 & -0.0053 & -0.0176 & & & & \\
\hline 9 & 0.0184 & 0.0049 & 0.0017 & 0.0006 & 0.0000 & -0.0007 & -0.0019 & -0.0054 & -0.0176 & & & \\
\hline 10 & 0.0184 & 0.0049 & 0.0018 & 0.0007 & 0.0002 & -0.0002 & -0.0008 & -0.0019 & -0.0054 & -0.0177 & & \\
\hline 11 & 0.0184 & 0.0049 & 0.0018 & 0.0008 & 0.0003 & 0.0000 & -0.0003 & -0.0008 & -0.0019 & -0.0055 & -0.0177 & \\
\hline 12 & 0.0185 & 0.0049 & 0.0018 & 0.0008 & 0.0004 & 0.0001 & -0.0001 & -0.0004 & -0.0008 & -0.0020 & -0.0055 & -0.0177 \\
\hline
\end{tabular}

the natural charges for each monomer unit in all clusters; the results are displayed in Table IX. All clusters show an asymmetric charge distribution where a somewhat greater charge magnitude is found at the positive end than at the negative end. For example, the charge magnitude at the positive end in the trimer $(0.01590 e)$ is $2.6 \%$ greater than that at the negative end $(-0.01548 e)$. For $n=12$, the charge magnitude at the positive end is about $4 \%$ greater. For a given cluster, the magnitude of the charge is considerably attenuated toward the interior of the chain.

Charge transfer from the positive end to the negative end of a given cluster results in a macroscopic dipole moment. The magnitude of this dipole is expected to increase with cluster size because the net charge transfer is also increased with chain length. This enhancement of the dipole is in agreement with the large cooperative dipole changes formerly discussed and shown in Table VI.

Perturbation theory energy analysis. A carefully examination of all possible interactions between "filled" (donor) Lewis-type NBOs and "empty" (acceptor) non-Lewis NBOs, allows us to get an estimate of their energetic importance by second-order perturbation theory. ${ }^{40}$ For each electron donor $\mathrm{NBO}(i)$ and acceptor $\mathrm{NBO}(j)$, the stabilization energy $E(2)$ associated with delocalization $i \rightarrow j$ is estimated as

$$
E(2)=\Delta E_{i j}=q_{i}\left(F_{i, j}\right)^{2} /\left(\varepsilon_{j}-\varepsilon_{i}\right)
$$

where $q_{i}$ is the donor orbital occupancy, $\varepsilon_{i}, \varepsilon_{j}$, are diagonal elements (orbital energies) and $F(i, j)$ is the off-diagonal NBO Fock matrix element.

In the $(d f a)_{n}$ clusters, the transfer of electron density from the lone pairs of each oxygen atom in the proton acceptor, $n_{\mathrm{O}}$, to the antibonding orbital of the $\mathrm{N}-\mathrm{H}$ bond in the proton donor, $\sigma^{*}(\mathrm{~N}-\mathrm{H})$, is seen to give the strongest stabilization energy. This is followed by the interaction between the oxygen lone pairs in the proton acceptor and the antibonding orbital of the $\mathrm{C}-\mathrm{H}$ bond of the proton donor, which is consistent with the presence of a secondary $\mathrm{H}$ bonding. Table $\mathrm{X}$ displays the combined stabilization energies, $\left[n_{\mathrm{O}}\right.$ $\left.\rightarrow \sigma^{*}(\mathrm{~N}-\mathrm{H})\right]+\left[n_{\mathrm{O}} \rightarrow \sigma^{*}(\mathrm{C}-\mathrm{H})\right]$, along the $(d f a)_{n}$ clusters. The stabilization effects are much stronger in the chain interior for all clusters as Fig. 11 shows for $n=12$. For a given pair of adjacent molecules, Table $\mathrm{X}$ shows a sizeable cooperative enhancement with cluster size that correlates closely with the cooperative structural changes, binding energies, ${ }^{1} \mathrm{H}-\mathrm{NMR}$ chemical shifts, and dipole enhancements discussed previously.

It is worth mentioning that electron density transferred from the electron donor subunit (Lewis base) B: into the antibonding $\sigma^{*}$ orbital of the electron acceptor (Lewis acid) $\mathrm{A}-\mathrm{H}$ is often used to explain both the elongation and the redshift of the $\mathrm{A}-\mathrm{H}$ bond in typical $\mathrm{H}$ bonds such as $\mathrm{N}-\mathrm{H} \cdots \mathrm{O}$. Table XI shows the NBO electron occupancy as-

TABLE X. NBO delocalization energies $\Delta E^{(2)}(\mathrm{kcal} / \mathrm{mol})$ for $(d f a)_{n}$ clusters. $^{\text {a }}$

\begin{tabular}{|c|c|c|c|c|c|c|c|c|c|c|c|}
\hline$n$ & $1 \rightarrow 2$ & $2 \rightarrow 3$ & $3 \rightarrow 4$ & $4 \rightarrow 5$ & $5 \rightarrow 6$ & $6 \rightarrow 7$ & $7 \rightarrow 8$ & $8 \rightarrow 9$ & $9 \rightarrow 10$ & $10 \rightarrow 11$ & $11 \rightarrow 12$ \\
\hline 2 & 10.96 & & & & & & & & & & \\
\hline 3 & 13.69 & 13.48 & & & & & & & & & \\
\hline 4 & 14.67 & 16.75 & 14.30 & & & & & & & & \\
\hline 5 & 15.03 & 17.83 & 17.73 & 14.60 & & & & & & & \\
\hline 6 & 15.23 & 18.34 & 19.00 & 18.20 & 14.78 & & & & & & \\
\hline 7 & 15.38 & 18.62 & 19.56 & 19.50 & 18.42 & 14.84 & & & & & \\
\hline 8 & 15.46 & 18.75 & 19.83 & 20.07 & 19.76 & 18.55 & 14.90 & & & & \\
\hline 9 & 15.39 & 18.82 & 19.99 & 20.36 & 20.35 & 19.89 & 18.61 & 14.92 & & & \\
\hline 10 & 15.49 & 18.86 & 20.06 & 20.52 & 20.64 & 20.50 & 19.97 & 18.69 & 14.98 & & \\
\hline 11 & 15.51 & 18.91 & 20.13 & 20.63 & 20.80 & 20.79 & 20.58 & 20.04 & 18.71 & 14.99 & \\
\hline 12 & 15.55 & 18.94 & 20.15 & 20.66 & 20.90 & 20.96 & 20.89 & 20.61 & 20.08 & 18.72 & 15.01 \\
\hline
\end{tabular}

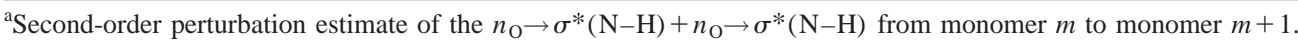




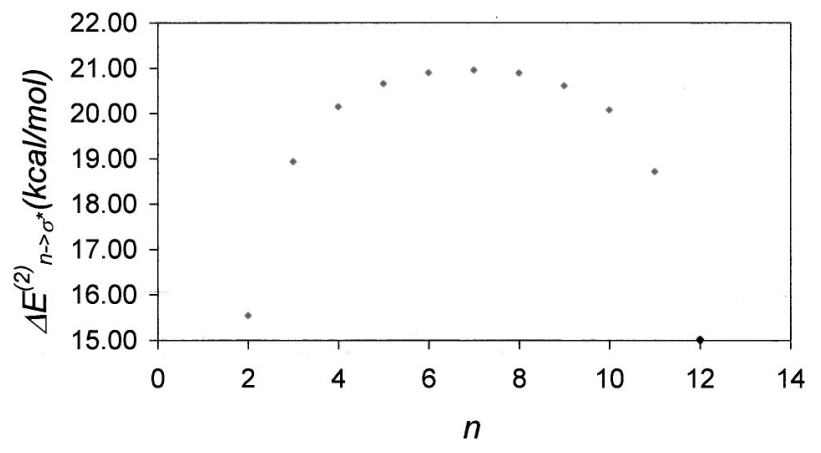

FIG. 11. Second-order perturbation theory estimates $\Delta E_{n \rightarrow \sigma^{*}}(\mathrm{kcal} / \mathrm{mol})$ of stabilization energy with each intermolecular $n_{\mathrm{o}} \rightarrow \sigma^{*}(\mathrm{~N}-\mathrm{H})+n_{\mathrm{o}}$ $\rightarrow \sigma^{*}(\mathrm{C}-\mathrm{H})$ charge transfer interaction in $(d f a)_{12}$.

sociated with the $\sigma^{*}(\mathrm{~N}-\mathrm{H})$ and $\sigma^{*}(\mathrm{C}-\mathrm{H})$ of the central molecule for odd $n$. The NBO analysis reveals an increase in the $\sigma^{*}(\mathrm{~N}-\mathrm{H})$ central molecule concomitant with an electron density decrease in the $\sigma^{*}(\mathrm{C}-\mathrm{H})$ with cluster size. An increase in the electron population of $\sigma^{*}(\mathrm{~N}-\mathrm{H})$ weakens the $\mathrm{N}-\mathrm{H}$ bond, as reflected in the elongation of the $\mathrm{N}-\mathrm{H}$ bond and in the redshift in the $\mathrm{N}-\mathrm{H}$ stretch frequency. A decrease in the electron population of $\sigma^{*}(\mathrm{C}-\mathrm{H})$ is reflected in the shortening of the $\mathrm{C}-\mathrm{H}$ bonds and in the blueshifts of the $\mathrm{C}-\mathrm{H}$ stretches.

The contraction of $\mathrm{C}-\mathrm{H}$ bonds and the blueshifts of the $\mathrm{C}-\mathrm{H}$ stretches upon $\mathrm{H}$-bond formation have been noted experimentally and theoretically for a number of systems. Recently, Hobza et al. ${ }^{41}$ proposed a two-step mechanism to explain this new type of $\mathrm{H}$ bond also known as improper, blueshifting $\mathrm{H}$ bonding. An improper $\mathrm{H}$ bond shows an unexpected blueshift of the A-H stretch. The proposed mechanism involves electron density transfer from the proton acceptor to the remote part of the proton donor, causing it to structurally relax, which in turn leads to a shortening of the $\mathrm{A}-\mathrm{H}$ bond, and to a blueshift in its stretching frequency. Such a mechanism may apply to the linear $(d f a)_{n}$ clusters where electron density can be transferred from the electron donor (proton acceptor) subunit to the remote oxygen atoms of the electron acceptor (proton donor) subunit. Table XI shows that the average oxygen lone pairs occupancy of the central molecule does increase with cluster size making the central molecule a better electron donor (or better proton acceptor).

TABLE XI. NBO electron occupancy $(e)$ for the central molecule in $(d f a)_{n}$ clusters.

\begin{tabular}{rccc}
\hline \hline$n$ & $\sigma^{\mathrm{a}}(\mathrm{N}-\mathrm{H})$ & $\sigma^{*}(\mathrm{C}-\mathrm{H})$ & $\left\langle n_{\mathrm{O}}\right\rangle^{\mathrm{a}}$ \\
\hline 1 & 0.0085 & 0.0482 & 1.9352 \\
3 & 0.0214 & 0.0420 & 1.9399 \\
5 & 0.0258 & 0.0400 & 1.9414 \\
7 & 0.0277 & 0.0394 & 1.9418 \\
9 & 0.0287 & 0.0391 & 1.9419 \\
11 & 0.0292 & 0.0389 & 1.9420 \\
\hline \hline
\end{tabular}

average value obtained by adding the occupancy of each lone pair and dividing by 2 .

\section{SUMMARY AND CONCLUSIONS}

Different indicators of $\mathrm{H}$-bond strength investigated by means of $a b$ initio calculations consistently show the existence of significant cooperative effects in a linear network of three-center bifurcated $\mathrm{H}$ bonds of the $\mathrm{A}_{1} \mathrm{HA}_{2}$ type. Such positive cooperativity helps rationalize the common occurrence of three-center $\mathrm{H}$ bonds in the crystals structures of many molecular systems. Thus, although three-center $\mathrm{H}$ bonds can be viewed as a consequence of proton deficiency, in some cases they may also be viewed as the natural result of an interaction that is itself energetically favorable, and that by means of cooperativity enhancements may even compete with the more conventional two-center $\mathrm{H}$ bonds.

The model system considered here benefits greatly from delocalization of the nitrogen lone pair over the $(\mathrm{O}=\mathrm{C}-\mathrm{N}-\mathrm{C}=\mathrm{O}) \pi$ system. Moreover, secondary $\mathrm{H}$ bonding between the oxygen atoms and the $\mathrm{C}-\mathrm{H}$ protons provides additional stability to the network. Upon formation of the bifurcated $\mathrm{H}$ bond, the intramolecular $\mathrm{N}-\mathrm{H}$ and $\mathrm{C}=\mathrm{O}$ bonds lengthen while the $\mathrm{N}-\mathrm{C}$ bond shortens. Also, the $\mathrm{O} \cdots \mathrm{O}$ separation is reduced by up to $0.10 \AA$, and the intermolecular $\mathrm{O} \cdots \mathrm{N}$ separation is reduced by up to $0.20 \AA$. This resonanceassisted delocalization facilitates the transfer of electron density from one molecule to another increasing the covalent character of this kind of hydrogen bonding.

The strong cooperative effects within one-dimensional chains of trans,trans-diformamide stress the need to develop molecular force fields that can provide a quantitatively accurate description of bifurcated $\mathrm{H}$ bonds. Some authors have suggested the use of a force field that includes inducible dipoles as well as fluctuating point charges. ${ }^{42}$ Such a model should be able, for example, to account for the fact that the energies of the individual bifurcated $\mathrm{H}$ bonds within a chain depend on both the size of the chain and the position of the individual $\mathrm{H}$ bond in that chain.

The results of this study can provide more insight, for example, into the complexing behavior of other trans-trans acyclic imides. Imides and fluorinated imides that adopt the trans-trans conformation in their homomeric crystal forms almost always form infinite chains linked by symmetrical or unsymmetrical bifurcated hydrogen bonds. ${ }^{43,44}$ This affects the cocrystallization and molecular recognition properties of these imides. Consideration of how a $\mathrm{H}$ bond guest could compete with and displace the H-bond pattern of the homomeric trans-trans form prior to crystal nucleation is a useful way to predict imide cocrystallization patterns.

\section{ACKNOWLEDGMENT}

This work was supported by start up funding and a Faculty Research and Development grant at DePaul University.

\footnotetext{
${ }^{1}$ A. Karpfen, Adv. Chem. Phys. 123, 469 (2002).

${ }^{2}$ S. Scheiner, Hydrogen Bonding: A Theoretical Perspective (Oxford University Press, New York, 1997), Chap. 5.

${ }^{3}$ G. R. Desiraju and T. Steiner, The Weak Hydrogen Bond (Oxford University Press, New York, 1997).

${ }^{4}$ G. A. Jeffrey, An Introduction to Hydrogen Bonding (Oxford University Press, New York, 1997), Chap. 6.

${ }^{5}$ H. Kleeberg, D. Klein, and W. A. P. Luck, J. Phys. Chem. 91, 3200 (1987).
} 
${ }^{6}$ E. Clementi, W. Kolos, G. C. Lie, and W. Ranghino, Int. J. Quantum Chem. 17, 377 (1980)

${ }^{7}$ P. L. Huyskens, J. Am. Chem. Soc. 99, 2578 (1977).

${ }^{8}$ P. Kollman, J. Am. Chem. Soc. 99, 4875 (1977).

${ }^{9}$ J. E. Del Bene and J. A. Pople, Chem. Phys. Lett. 4, 426 (1969).

${ }^{10}$ H. S. Frank and W. Y. Wen, Discuss. Faraday Soc. 24, 133 (1957).

${ }^{11}$ A. K. Sum and S. I. Sandler, J. Phys. Chem. 104, 1121 (2000).

${ }^{12}$ R. D. Parra and X. C. Zeng, J. Chem. Phys. 110, 6329 (1999).

${ }^{13}$ W. E. Doering, R. D. Parra, and X. C. Zeng, J. Mol. Struct.: THEOCHEM 431, 119 (1998).

${ }^{14}$ F. C. Hagemeister, C. J. Gruenloh, and T. S. Zwier, J. Phys. Chem. A 102, 82 (1998).

${ }^{15}$ O. Mó, M. Yáñez, and J. Elguero, J. Chem. Phys. 107, 3592 (1997).

${ }^{16}$ K. R. Liedl, R. T. Kroemer, and B. M. Rode, Chem. Phys. Lett. 246, 455 (1995).

${ }^{17}$ A. Karpfen and O. Yanovitskii, J. Mol. Struct.: THEOCHEM 314, 211 (1994).

${ }^{18}$ A. Karpfen, in Molecular Interactions, edited by S. Scheiner (Wiley, New York, 1997), Chap. 8.

${ }^{19}$ B. F. King and F. Weinhold, J. Chem. Phys. 103, 333 (1995).

${ }^{20}$ S. Suhai, J. Chem. Phys. 101, 9766 (1994).

${ }^{21}$ R. Ludwig, O. Reis, R. Winter, F. Weinhold, and T. C. Farrar, J. Phys. Chem. B 102, 9312 (1998).

${ }^{22}$ H. Guo, N. Gresh, B. P. Roques, and D. R. Salahub, J. Phys. Chem. B 104, 9746 (2000).

${ }^{23}$ K. Nadya, P. Lillyrose, E. del Rio, and J. J. Dannenberg, J. Am. Chem. Soc. 123, 4348 (2001).

${ }^{24}$ I. Rozas, I. Alkorta, and J. Elguero, J. Phys. Chem. A 102, 9925 (1998).

${ }^{25}$ R. D. Parra, M. Furukawa, B. Gong, and X. C. Zeng, J. Chem. Phys. 115, 6030 (2001).

${ }^{26}$ J. H. Yang and S. H. Gellman, J. Am. Chem. Soc. 120, 9090 (1998).
${ }^{27}$ J. H. Yang, L. A. Christianson, and S. H. Gellman, Org. Lett. 1, 11 (1999).

${ }^{28}$ R. D. Parra, B. Gong, and X. C. Zeng, J. Chem. Phys. 115, 6036 (2001).

${ }^{29}$ A. Masunov and J. J. Dannenberg, J. Phys. Chem. B 104, 806 (2000).

${ }^{30}$ S. Dong, R. Ida, and G. Wu, J. Phys. Chem. A 104, 1194 (2000).

${ }^{31}$ T. Lan and L. W. McLaughin, J. Am. Chem. Soc. 123, 2064 (2001) and references therein.

${ }^{32}$ M. Meyer, M. Brandl, and J. Sühnel, J. Phys. Chem. A 105, 8223 (2001).

${ }^{33}$ G. F. Fabiola, S. Krishnaswamy, V. Nagarajan, and V. Pattabhi, Acta Crystallogr., Sect. D: Biol. Crystallogr. D53, 316 (1997).

${ }^{34}$ M. J. Frish, G. W. Trucks, H. B. Schlegel et al., Gaussian 98, Revision A.9, Gaussian, Inc., Pittsburgh, PA, 1998.

${ }^{35}$ A. J. Stone, The Theory of Intermolecular Forces (Oxford University Press, Oxford, 1997), p. 67.

${ }^{36} \mathrm{~S}$. L. Price, in Molecular Interactions-From van der Waals to Strongly Bound Molecular Complexes, edited by S. Scheiner (Wiley, Chichester, 1997), Chap. 9.

${ }^{37}$ M. M. Szczesniak, R. J. Brenstein, S. M. Cybulski, and S. Scheiner, J. Phys. Chem. 94, 1781 (1990).

${ }^{38}$ S. Scheiner, Y. Gu, and T. Kar, J. Mol. Struct.: THEOCHEM 500, 441 (2000).

${ }^{39}$ D. B. Chesnut and C. G. Phung, Chem. Phys. 147, 91 (1990).

${ }^{40}$ E. D. Glendening, J. K. Badenhoop, A. E. Reed, J. E. Carpenter, and F. Weinhold, NBO 4.0. Theoretical Chemistry Institute, University of Wisconsin, Madison, 1996.

${ }^{41}$ B. J. van der Veken, W. A. Herrebout, R. Szostak, D. N. Schepkin, Z. Havlas, and P. Hobza, J. Am. Chem. Soc. 123, 12290 (2001).

${ }^{42}$ H. A. Stern, G. A. Kaminski, J. L. Banks, R. Zhou, B. J. Berne, and R. A. Friesner, J. Phys. Chem. B 103, 4730 (1999).

${ }^{43}$ M. C. Etter and S. M. Reutzel, J. Am. Chem. Soc. 113, 2586 (1991).

${ }^{44}$ P. M. Narula, C. S. Day, B. A. Powers, M. A. Odian, A. Lachgar, W. T. Pennington, and R. E. Noftle, Polyhedron 18, 1751 (1999). 